\title{
Experimental and Theoretical Steady State Maximum Temperature Local- ization along an Exothermic Tubular Chemical Reactor
}

\author{
L. Vernières-Hassimi, M.A. Abdelghani-Idrissi* and D. Seguin \\ Laboratoire Sécurité des Procédés Chimiques, Equipe Stabilité Thermique des Procédés, Université de Rouen - IUT,
Rue Lavoisier 76821 Mont Saint Aignan cedex, France
}

\begin{abstract}
This article deals with the experimental and theoretical localization of steady state maximum temperature along an exothermic tubular reactor in counter current flow configuration; which represents a key parameter for safety in the chemical engineering processes. The fluid flowing in the inner tube is a mixture of sodium thiosulfate solution in reaction with hydrogen peroxide. To control the reactive fluid temperature, the inner tube is cooled with a refrigerant fluid flowing through the annular space. The steady state is obtained from the resolution of the nonlinear partial differential equations with the McCormack numerical method. The steady state temperature of the reactive fluid along the tubular reactor presents a maximum value due to the exothermic chemical reaction. The maximum temperature value which represents the critical point of the reactor is investigated. In particular its localization is studied for the first time according to various parameters such as flow rates, reactant concentrations and inlet temperatures.
\end{abstract}

\section{INTRODUCTION}

Catastrophic industrial accidents such as Feyzin in 1966, Seveso in 1976 (Homberger et al., 1979) [1], Bhopal in 1984 (Gupta, 1979) [2]... marked the industrial activities and have attracted attention to the hazards of chemical industries. Moreover, these industries become increasingly complex with advances in technology, which increase the potential risks. For these reasons, various studies were carried out and several methods of risk analysis and prevention were developed. Thus, the chemical industry efficiencies are not considered only in term of productivity and quality, but also in term of safety and environmental protection. Gygax presented the extension of the chemical engineering principles to the study of potential runaway reactions (Gygax, 1988) [3]. The thermal runaway corresponds to the loss of temperature control of any enclosed exothermic chemical substance (Vince, 2000) [4], (Crowl, 2002) [5]. The increase of the reactive mixture temperature is due to the presence of exothermic phenomena when the generated calorific power by the chemical conversions is more important than the heat capacity of cooling. The acceptable maximum temperature then defines safety and quality, particularly when dangerous reactions of decomposition or parasitic reactions can be initiated. Maestri and Rota (Maestri, 2006) [6] have coupled the limits diagrams of reactivity versus exothermicity with temperature diagrams for thermally safe operation of liquidliquid semi batch reactors. Those diagrams make it possible to determine the increase of the maximum temperature for a certain number of operating conditions.

Note that, the batch reactors present the problem of thermal accumulation. The continuous tubular reactors have the advantage of being intrinsically safer because the instantaneous volume is generally reduced; which decreases the poten-

\footnotetext{
*Address correspondence to this author at the Laboratoire Sécurité des Procédés Chimiques, Equipe Stabilité Thermique des Procédés, Université de Rouen - IUT, Rue Lavoisier 76821 Mont Saint Aignan cedex, France; Tel: 33 (0) 235146 369; Fax: 33 (0) 235146 263;

E-mail: Ahmed.Abdelghani@univ-rouen.fr
}

tial risk (Vernières-Hassimi, 2006) [7]. However, the equipment is never safe from failure. For this reason, safety assessment of the tubular reactors is necessary. Madellin and Luss investigated the steady state multiplicity and stability in a counter-current cooled tubular reactor (Madellin, 1972) [8]. Efficient refrigeration to ensure safe operation was investigated by combining co-current and counter-current configurations (de Morais, 2003) [9], (de Morais, 2004) [10]. For non-adiabatic tubular reactors, involving strong exothermic reactions, frequent operational problems are related to the occurrence of hot spots. Preventing the development of hot spots is important given that they may lead, in the case of competitive reactions to a decrease of selectivity, catalyst deactivation and particularly to reactor temperature runaways. The maximum temperature and its localization in the distributed systems, in particular in the case of a continuous tubular reactor, can be modified when the input parameters change with the disturbances caused by other elements connected to the reactor. It is thus necessary to study the variation of the maximum temperature and its localization along the reactor with respect to the input parameters such as reactant concentrations, inlet temperatures and flow rates. This paper deals with the steady state maximum temperature, which represents the critical point in term of safety of the reactor, and its localization in particular is studied for the first time according to various parameters such as flow rates, reactant concentrations and inlet temperatures.

\section{SET-UP DESCRIPTION AND MODELING}

Fig. (1) illustrates the set-up of the tubular exothermic chemical reactor designed and assembled in the laboratory in order to validate experimentally the theoretical results presented in this article.

The mixture of hydrogen peroxide and sodium thiosulfate flows in the glass inner tube while the refrigerant fluid circulates in counter current configuration through the glass outer tube. The composition in several modules provides a flexible tubular chemical reactor. The length of each module is 0.75 $\mathrm{m}$. Temperature sensors are placed at the inlet and outlet of 


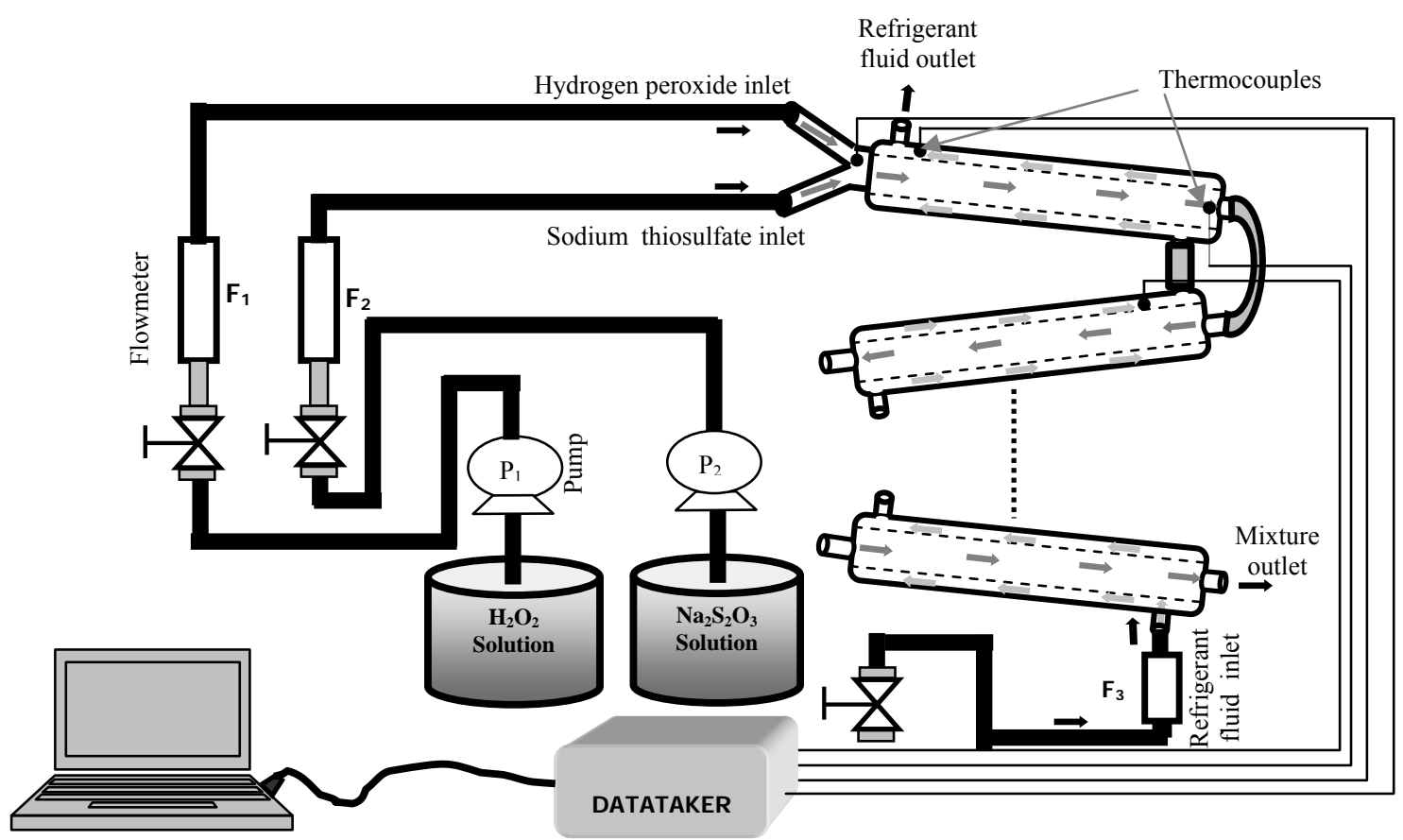

Fig. (1). Experimental set-up of the tubular reactor with its data acquisition system.

each module in order to measure the temperatures along the tubular reactor. The probes are connected to a data acquisition system to collect the data on a workstation. The pumps allow the flow of the mixture of sodium thiosulfate and hydrogen peroxide in the glass inner tube.

The geometrical and physical parameters of the tubular reactor are indicated in Table $\mathbf{1}$.

The choice of this reaction was based on well-known kinetics reaction parameters in open literature (Cohen and Spencer, 1962) [11]. Many chemical reactions were highlighted in this reference:

$$
2 \mathrm{Na}_{2} \mathrm{~S}_{2} \mathrm{O}_{3}+\mathrm{H}_{2} \mathrm{O}_{2} \rightarrow \mathrm{Na}_{2} \mathrm{~S}_{4} \mathrm{O}_{6}+2 \mathrm{NaOH}
$$

$\mathrm{Na}_{2} \mathrm{~S}_{2} \mathrm{O}_{3}+\mathrm{H}_{2} \mathrm{O}_{2} \rightarrow \mathrm{Na}_{2} \mathrm{~S}_{2} \mathrm{O}_{4}+\mathrm{H}_{2} \mathrm{O}$

$3 \mathrm{Na}_{2} \mathrm{~S}_{2} \mathrm{O}_{3}+4 \mathrm{H}_{2} \mathrm{O}_{2} \rightarrow 2 \mathrm{Na}_{2} \mathrm{~S}_{3} \mathrm{O}_{6}+2 \mathrm{NaOH}+3 \mathrm{H}_{2} \mathrm{O}$

$3 \mathrm{Na}_{2} \mathrm{~S}_{2} \mathrm{O}_{3}+5 \mathrm{H}_{2} \mathrm{O}_{2} \rightarrow \mathrm{Na}_{2} \mathrm{~S}_{4} \mathrm{O}_{6}+2 \mathrm{Na}_{2} \mathrm{SO}_{4}+5 \mathrm{H}_{2} \mathrm{O}$

$2 \mathrm{Na}_{2} \mathrm{~S}_{2} \mathrm{O}_{3}+4 \mathrm{H}_{2} \mathrm{O}_{2} \rightarrow \mathrm{Na}_{2} \mathrm{~S}_{3} \mathrm{O}_{6}+\mathrm{Na}_{2} \mathrm{SO}_{4}+4 \mathrm{H}_{2} \mathrm{O}$

The reaction rate is given by the Arrhenius relation:
$r=A_{0} \exp \left(-\frac{E a}{R T_{r}}\right) C_{A}^{\alpha} C_{B}^{\beta}$

Where $T_{r}$ represents the mixture temperature, $C_{A}$ and $C_{B}$ are respectively the hydrogen peroxide and the sodium thiosulfate concentration, $\mathrm{Ea}$ is the activation energy, $\mathrm{R}$ is the perfect gas constant and $\mathrm{A}_{0}$ represents the frequency factor.

Cohen and Spencer showed that the main reaction $(\mathrm{V})$ is obtained in majority when $\frac{\left[\mathrm{H}_{2} \mathrm{O}_{2}\right]}{\left[\mathrm{S}_{2} \mathrm{O}_{3}{ }^{2-}\right]} \geq 1.96$ (Cohen and Spencer, 1962) [11]. In this case, the parameters $\alpha$ and $\beta$ do not vary and were identified as:

$\alpha=1.5$ and $\beta=0.6$.

The values of the reaction kinetics parameters were determined by Aimé (Aimé, 1991) [12]:

$\left\{\begin{array}{l}A_{0}=6.75 \quad 10^{8} \mathrm{~L} \mathrm{~mol}^{-1} \mathrm{~s}^{-1} \\ E a=80256 \mathrm{~J} \cdot \mathrm{mol}^{-1} \\ \Delta \mathrm{H}=-553 \mathrm{~kJ} \cdot \mathrm{mol}^{-1}\end{array}\right.$

Table 1. Geometrical and Physical Parameters of the Tubular Chemical Reactor

\begin{tabular}{|c|c|c|c|c|c|c|}
\hline & \multicolumn{3}{|c|}{ Geometrical Parameters } & \multicolumn{3}{|c|}{ Physical Parameters } \\
\hline outer pipe & $3 \times 10^{-2}$ & $2 \times 10^{-3}$ & 8.6 & 1.22 & 380 & 2200 \\
\hline
\end{tabular}


An averaged value of the enthalpy is considered.

The model of this chemical system is obtained from the energy and mass balances taking into account the reaction chemical kinetics. The assumptions made are:

- Fluids are in turbulent flow since the Reynolds number is $\operatorname{Re}>3000$

- Radial variation of temperature is neglected; the Peclet number in our experiments is $\mathrm{Pe} \gg 1$

- Fluids are incompressible and single phased

- Thermophysical properties of the fluids are assumed to be constant

- Heat exchange with external environment is neglected

In order to obtain the governing differential equations in steady state, the tubular reactor is subdivided in many elemental volumes of length $\mathrm{dx}$. While flowing through the elemental volume, the mixture reacts as a source of energy and transfers convective heat to the wall resulting in change of its outlet enthalpy. Energy balance applied to a differential volume of reactive fluid and coolant fluid leads to the first and second equations of system (2) after simplification and rearrangement. Mass balance applied to the reactant fluid for both hydrogen peroxide and sodium thiosulfate gives the third and the fourth equations of system (2).

$$
\left\{\begin{array}{l}
0=-v_{r} \frac{d T_{r}(x)}{d x}+K_{r}\left(T_{c}(x)-T_{r}(x)\right) \\
-\frac{\Delta H}{\rho_{r} C_{p r}} A_{0} \exp \left(-\frac{E a}{R T_{r}}\right) C_{A}^{\alpha} C_{B}^{\beta} \\
0=v_{c} \frac{d T_{c}(x)}{d x}+K_{c}\left(T_{r}(x)-T_{c}(x)\right) \\
0=-v_{r} \frac{d C_{A}(x)}{d x}+v_{A} A_{0} \exp \left(-\frac{E a}{R T_{r}}\right) C_{A}^{\alpha} C_{B}^{\beta} \\
0=-v_{r} \frac{d C_{B}(x)}{d x}+v_{B} A_{0} \exp \left(-\frac{E a}{R T_{r}}\right) C_{A}^{\alpha} C_{B}^{\beta}
\end{array}\right.
$$

$\mathrm{v}_{\mathrm{r}}$ and $\mathrm{v}_{\mathrm{c}}$ are respectively the mean velocity of the reactional fluid and the cooling fluid.

$\mathrm{Kr}$ and the $\mathrm{Kc}$ are the coupling coefficients related to the convective heat transfer coefficients and to the thermal conductivity of the separating wall, and are given by the following expressions:

$$
\mathrm{K}_{\mathrm{r}}=\frac{\mathrm{UA}}{\mathrm{C}_{\mathrm{r}}^{*}} \quad \mathrm{~K}_{\mathrm{c}}=\frac{\mathrm{UA}}{\mathrm{C}_{\mathrm{c}}^{*}}
$$

$\mathrm{U}$ is the global heat transfer coefficient and is given below:

$\frac{1}{\mathrm{U}}=\frac{1}{\mathrm{~h}_{\mathrm{r}}}+\frac{\mathrm{e}_{\mathrm{i}}}{\lambda}+\frac{1}{\mathrm{~h}_{\mathrm{c}}}$

$\mathrm{A}$ is the heat transfer area between the reactive fluid and the cooling fluid.

$\mathrm{C}^{*} \mathrm{r}$ and $\mathrm{C}^{*} \mathrm{c}$ are respectively the heat capacity of the reactive fluid and the cooling fluid, which play an important role in defining the steady state of the tubular reactor. These parameters are functions of the temperature but can be considered uniform along the tubular reactor according to the temperature range of this study.
The distributed boundary conditions are the reactive and cooling fluids inlet temperatures, and the inlet concentrations:

$$
\left\{\begin{array}{l}
T_{r}(x=L)=T_{r, i n} \\
T_{c}(x=0)=T_{c, i n} \\
C_{A}(x=L)=C_{A, i n} \\
C_{B}(x=L)=C_{B, i n}
\end{array}\right.
$$

The convective heat transfer coefficient in the inner tube is obtained from the Colburn correlation (Colburn, 1933) [13] and is given as:

$$
N u_{r}=0.023 \operatorname{Pr}_{r}^{1 / 3} \operatorname{Re}_{r}^{4 / 5}\left(\frac{\mu}{\mu_{w}}\right)^{0.14}
$$

Kawamura proposed two correlations for turbulent annular flow as a function of radius ratio of inner and outer tube (Kawamura, 1973) [14]:

$$
N u_{c}=0.022 \varphi_{i} \operatorname{Pr}_{c}^{1 / 2} \operatorname{Re}_{c}^{4 / 5}
$$

The accommodation factor $\varphi_{\mathrm{i}}$ represents the ratio of the shear stress on the inner wall to the average shear stress on the inner and outer walls. More details of these correlations are given in reference (Kawamura, 1973) [14].

To solve system (2), the iterative McCormack method is used in Matlab ${ }^{\circledR}$ environment (McCormak, 1971) [15]. This method is based on a discretization of the first order equations with regular steps. A predictor and corrector constitute the scheme of this method. The iterative predictor scans the tubular reactor to evaluate the temperatures and the concentrations by taking account of the boundary conditions of one side, and the corrector scans backwards from the reactor to adjust the values of the temperatures and the concentrations by considering the other side's boundary conditions. This method makes it possible to take into account the non linearities due to the exponential factor of the reaction kinetics.

\section{RESULTS AND DISCUSSIONS}

The model presented in the previous section is at first validated with experimental results obtained on the experimental set-up described before. It should be noted that for all

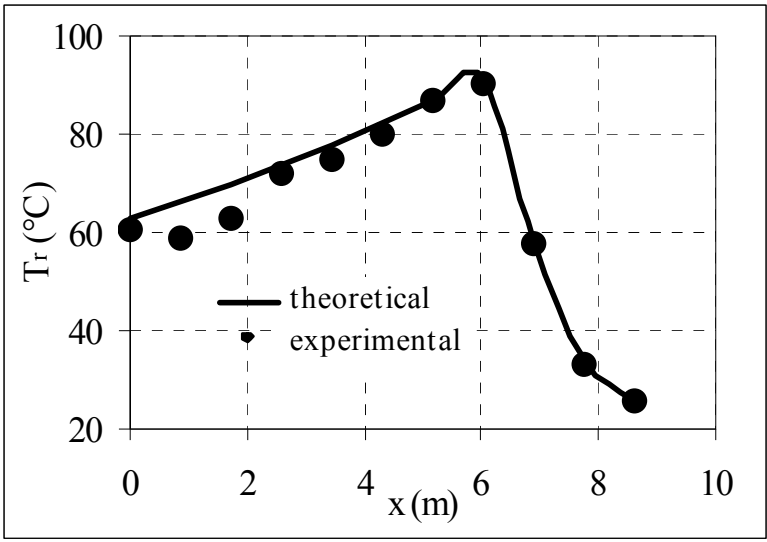

Fig. (2). Reactive fluid temperature along the tubular reactor $(\mathrm{Qr}=$ $0.06 \mathrm{~kg} / \mathrm{s}$ ). 
presented results in this paper, the inlet of the reagents corresponds to the position $\mathrm{x}=\mathrm{L}$ and their outlet corresponds to the position $x=0$. Fig. (2) shows the experimental and theoretical profiles of reactive fluid temperature along the tubular reactor.

The experimental conditions of Fig. (2) are indicated in Table 2.

Table 2. Experimental Conditions of Fig. (2)

\begin{tabular}{|c|c|c|c|c|c|}
\hline $\begin{array}{c}\mathbf{C}_{\mathrm{A}, \mathbf{i n}} \\
\left(\mathbf{m o l} . \mathbf{m}^{-3}\right)\end{array}$ & $\begin{array}{c}\mathbf{C}_{\mathbf{B}, \mathbf{i n}} \\
\left(\mathbf{m o l} . \mathbf{m}^{-3}\right)\end{array}$ & $\begin{array}{c}\mathbf{Q}_{\mathbf{r}} \\
(\mathbf{k g} / \mathbf{s})\end{array}$ & $\begin{array}{c}\mathbf{Q}_{\mathbf{c}} \\
(\mathbf{k g} / \mathbf{s})\end{array}$ & $\begin{array}{c}\mathbf{T}_{\mathbf{r}, \text { in }} \\
\left({ }^{\circ} \mathbf{C}\right)\end{array}$ & $\begin{array}{c}\mathbf{T}_{\mathbf{c}, \text { in }} \\
\left({ }^{\circ} \mathbf{C}\right)\end{array}$ \\
\hline \hline 1300 & 545 & 0.060 & 0.268 & 25.5 & 20.7 \\
\hline
\end{tabular}

The experimental temperature presents a maximum value and corroborates the theoretical results. As described in the previous sections, the temperature of the reactive fluid increases and reaches its maximum value $T_{r, \max }$ before decreasing along the inner pipe.

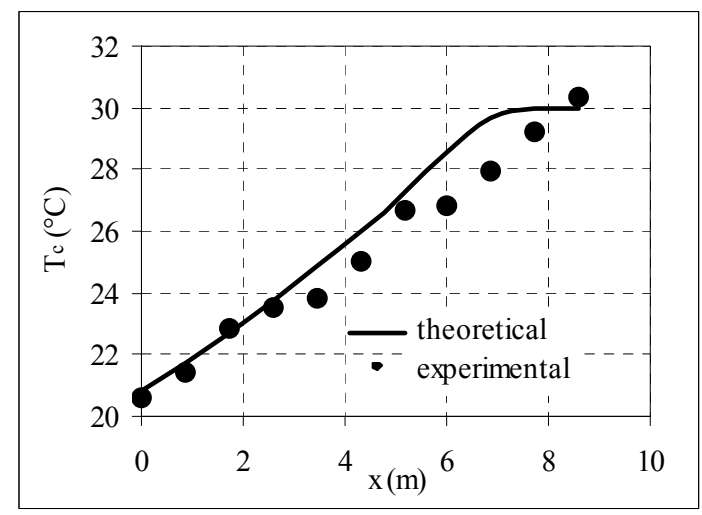

Fig. (3). Cooling fluid temperature along the tubular reactor $(\mathrm{Qr}=$ $0.06 \mathrm{~kg} / \mathrm{s})$.

With the same experimental conditions indicated in Table 2, Fig. (3) shows the experimental and theoretical temperature of the cooling fluid along the tubular reactor. The cooling fluid temperature is an increasing function with the position along the reactor.

Fig. (4) shows the concentrations of sodium thiosulfate and hydrogen peroxide along the reactor obtained with the

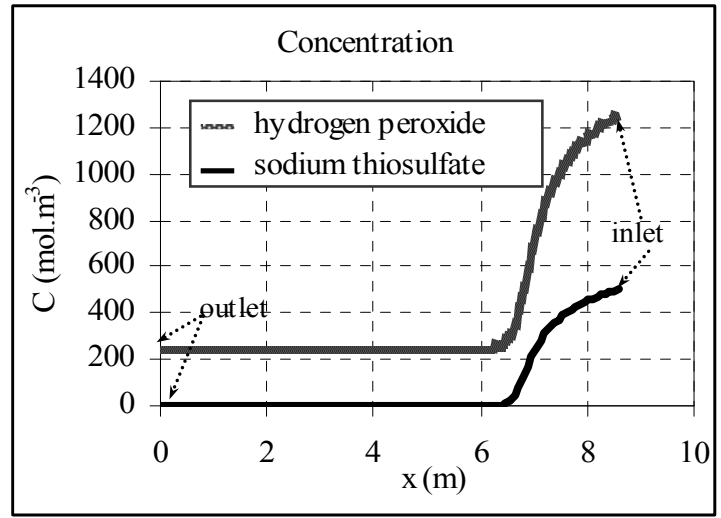

Fig. (4). Concentrations of reagents along the tubular reactor $(\mathrm{Qr}=$ $0.06 \mathrm{~kg} / \mathrm{s}$ ). same conditions as figures 2 and 3. The maximum temperature is reached when the chemical reaction is complete, as illustrated on the curves of the figure 4 representing concentration profiles along the tubular reactor.

The theoretical results of Figs. (2), (3) and (4) are obtained with the parameters reported on Table (3).

Table 3. Simulation Parameters of Figs. (2-4)

\begin{tabular}{|c|c|c|c|c|c|}
\hline & $\mathbf{R e}$ & $\mathbf{P r}$ & $\mathbf{N u}$ & $\mathbf{s h}\left(\mathbf{W} / \mathbf{m}^{2} \mathbf{K}\right)$ & $\mathbf{U}\left(\mathbf{W} / \mathbf{m}^{2} \mathbf{K}\right)$ \\
\hline \hline $\begin{array}{c}\text { Reactive } \\
\text { fluid }\end{array}$ & 6280 & 4.6 & 41.8 & 1636 & \\
\hline $\begin{array}{c}\text { Coolant } \\
\text { fluid }\end{array}$ & 6780 & 6.8 & 70.5 & 2308 & 397 \\
\hline
\end{tabular}

In order to validate the model, other experiments were performed as illustrated by Figs. $(\mathbf{5}, \mathbf{6})$ and (7) obtained with a different value of the reactive fluid flow rate $(\mathrm{Qr}=0.147$ $\mathrm{kg} / \mathrm{s})$.

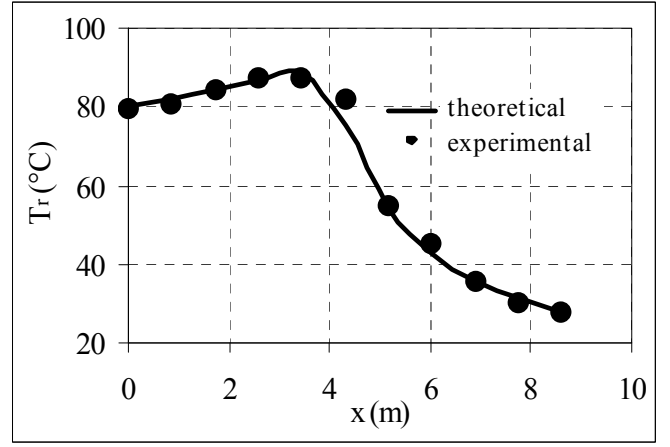

Fig. (5). Reactive fluid temperature along the tubular reactor $(\mathrm{Qr}=$ $0.147 \mathrm{~kg} / \mathrm{s})$.

The model used with the assessment methods of the heat transfer coefficients and the chemical reaction kinetics lead to results that are in agreement with those obtained from the experimental set-up.

Note that when the flow rate increases, the maximum temperature of the reactant fluid is shifted toward its outlet. On the other hand, the value of the maximum temperature is relatively independent of the flow rate of the reactive fluid. After reaching the maximum temperature, the heat transfer phenomena are dominant for cooling the product.

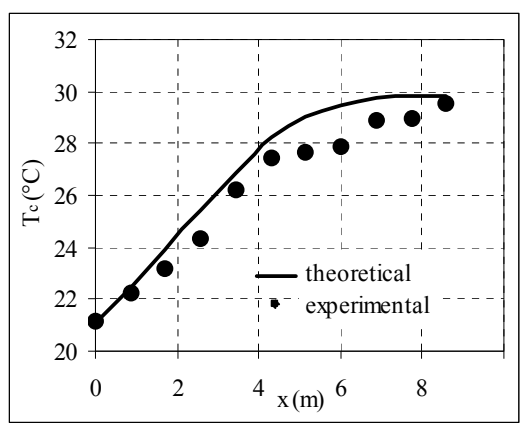

Fig. (6). Cooling fluid temperature along the tubular reactor with $\mathrm{Qr}=0.147 \mathrm{~kg} / \mathrm{s}$. 
As illustrated in Fig. (7), when the reactive fluid flow rate increases, the complete chemical conversions occur at a position shifted toward the outlet in correlation with the maximum temperature.

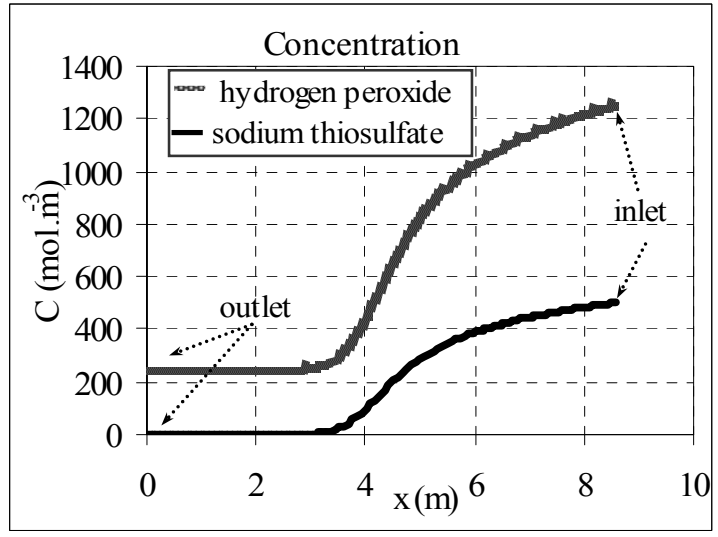

Fig. (7). Reagents concentrations along the reactor with $\mathrm{Qr}=0.147$ $\mathrm{kg} / \mathrm{s}$.

The theoretical results are obtained with the parameters indicated on Table (4).

Table 4. Simulation Parameters of Figs. (5-7)

\begin{tabular}{|c|c|c|c|c|c|}
\hline & $\mathbf{R e}$ & $\mathbf{P r}$ & $\mathbf{N u}$ & $\mathbf{h}\left(\mathbf{W} / \mathbf{m}^{2} \mathbf{K}\right)$ & $\mathbf{U}\left(\mathbf{W} / \mathbf{m}^{2} \mathbf{K}\right)$ \\
\hline \hline $\begin{array}{c}\text { Reactive } \\
\text { fluid }\end{array}$ & 15389 & 4.6 & 85.6 & 2783 & 453 \\
\hline
\end{tabular}

The parameters linked to the coolant fluid are the same of that indicated on Table 3.

\section{INFLUENCE OF THE HYDROGEN PEROXIDE CONCENTRATION}

In order to highlight the influence of the flow rate of the reactive fluid for various concentrations of the hydrogen peroxide, the maximum temperature and its localization are extracted from the temperature profiles along the tubular reactor. The extracted results are presented on Fig. (8) which illustrates the variation of the maximum temperature (Fig. $(\mathbf{8 a})$ ) and its localization (Fig. (8b)) according to the reactive fluid flow rate for various hydrogen peroxide concentrations. It should be noted that the maximum temperature increases when the concentration of hydrogen peroxide increased. Indeed, an increase in the concentration at the inlet $\mathrm{C}_{\mathrm{A}, \text { in }}$, increases the probability of the collision of the molecules in reaction. The localization of the maximum temperature indicated on the curves of Fig. (8b) is a decreasing linear function according to the reactive fluid flow rate.

It should be noted also that the more the concentration of hydrogen peroxide increases, the more the position of the maximum temperature move toward the reactor inlet. Indeed, the chemical kinetics reaction increases with the concentration.

Fig. (9) shows the confrontation of the theoretical results with the experimental values of the maximum temperature localization according to the reactive fluid flow rate.
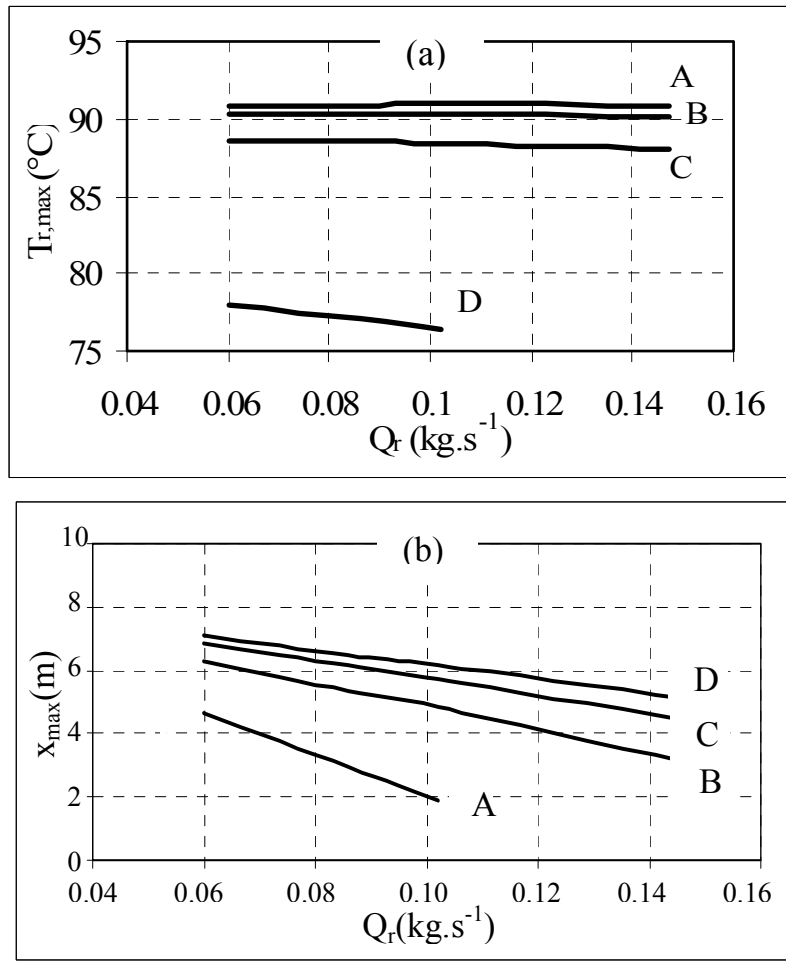

Fig. (8). Maximum temperature (a) and its localization (b) according to the reactive fluid flow rate.

$\mathrm{C}_{\mathrm{B}, \mathrm{in}}=500 \mathrm{~mol} \cdot \mathrm{m}^{-3}, \mathrm{Q}_{\mathrm{c}}=0.270 \mathrm{~kg} \cdot \mathrm{s}^{-1}$,

$\mathrm{T}_{\mathrm{r}, \mathrm{in}}=27.9^{\circ} \mathrm{C}, \mathrm{T}_{\mathrm{c}, \text { in }}=21.0^{\circ} \mathrm{C}$

(A) $\mathrm{C}_{\mathrm{A}, \text { in }}=1500 \mathrm{~mol} \cdot \mathrm{m}^{-3}$; (B) $\mathrm{C}_{\mathrm{A}, \text { in }}=1400 \mathrm{~mol} \cdot \mathrm{m}^{-3}$

(C) $\mathrm{C}_{\mathrm{A}, \text { in }}=1250 \mathrm{~mol} \cdot \mathrm{m}^{-3}$; (D) $\mathrm{C}_{\mathrm{A}, \text { in }}=1000 \mathrm{~mol} \cdot \mathrm{m}^{-3}$

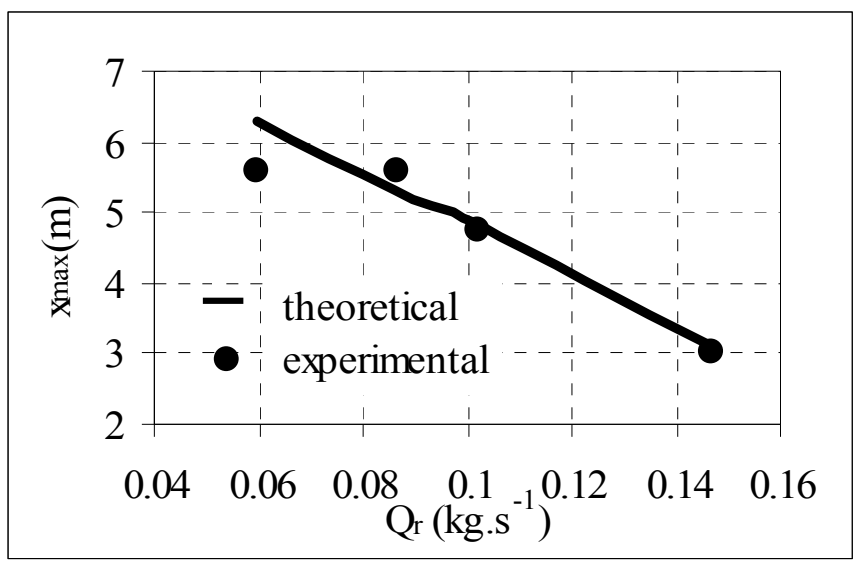

Fig. (9). Experimental and theoretical localization of the maximum temperature versus the flow rate of the reactive fluid.

The maximum temperature position is obtained with an accuracy of $\pm 0.20 \mathrm{~m}$. The theoretical results are in agreement with those obtained experimentally. Note that the difference of approximately $12 \%$ observed for a flow rate of $0.06 \mathrm{~kg} . \mathrm{s}^{-1}$ is due to the variation of the inlet temperature of the reagents which depends on the environment temperature of the experimental device in the laboratory. Considering the linearity of the maximum position according to the flow rate, $\mathrm{x}_{\max }$ can be expressed according to the mean velocity of the reactive fluid $\mathrm{v}_{\mathrm{r}}$ by the following relation: 
$\mathrm{X}_{\text {max }}=-\tau_{\max } \mathrm{V}_{\mathrm{r}}+\mathrm{L}$

where the characteristic time $\tau_{\max }$ represents the reactive fluid residence time to reach the maximum temperature position.

In order to show the influence of the hydrogen peroxide concentration, Fig. (10) illustrates the evolution of the maximum temperature and its localization for various flow rates of the reactive fluid. The graph $(\mathrm{A})$ corresponds to the maximum temperature as function of $\mathrm{C}_{\mathrm{B} \text {,in }}$ for different values of the reactive fluid flow rate. This graph shows the nonlinear evolution of the maximum temperature of the reactive fluid according to the hydrogen peroxide concentration for various reactive fluid flows.
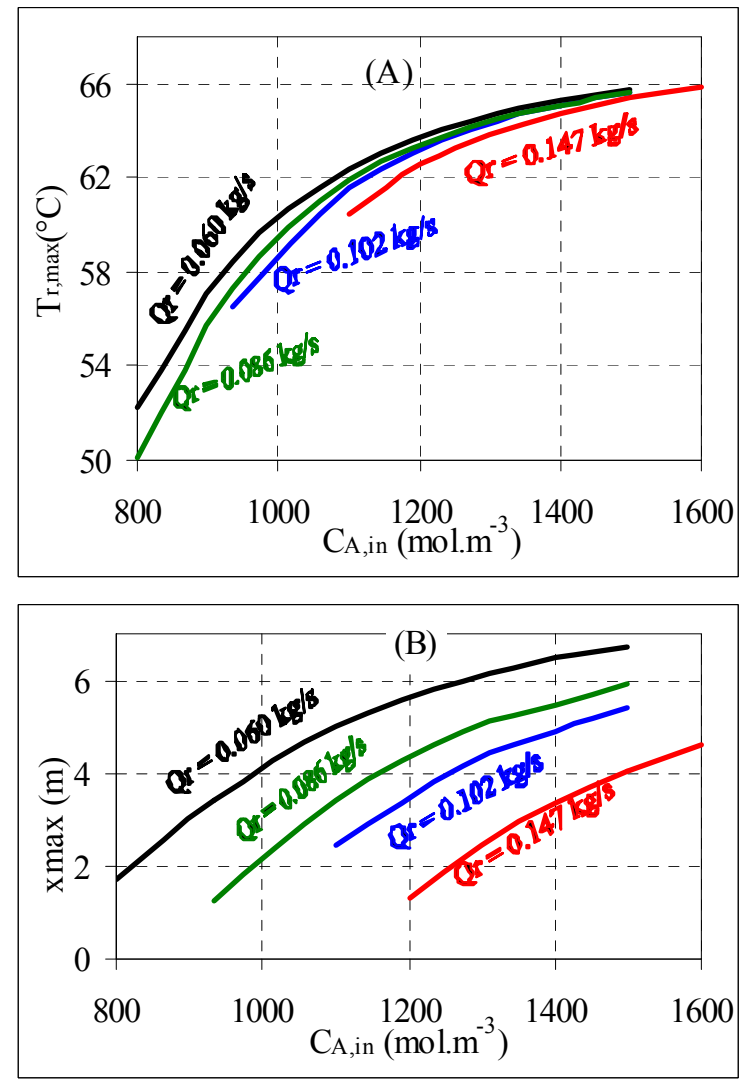

Fig. (10). Maximum temperature (A) and its localization (B) as function of the hydrogen peroxide concentration for different values of the reactive fluid flow rate.

$\mathrm{C}_{\mathrm{B}, \mathrm{in}}=300$ mol.m $\mathrm{m}^{-3}, \mathrm{~T}_{\mathrm{r}, \mathrm{in}}=29.5^{\circ} \mathrm{C}, \mathrm{T}_{\mathrm{c}, \mathrm{in}}=21^{\circ} \mathrm{C}$, $\mathrm{Q}_{\mathrm{c}}=0.270 \mathrm{~kg} \cdot \mathrm{s}^{-1}$

The hydrogen peroxide concentration seems to have less influence on maximum temperature value compared to that of the sodium thiosulfate concentration. The maximum temperature localization according to the hydrogen peroxide concentration for various reactive fluid flow rates is shown on the graph (B). This graph illustrates the non linear increasing of the localization with the hydrogen peroxide concentration.

Fig. (11) shows the experimental and theoretical temperature of the reactive fluid along the tubular reactor for two values of the hydrogen peroxide concentration.

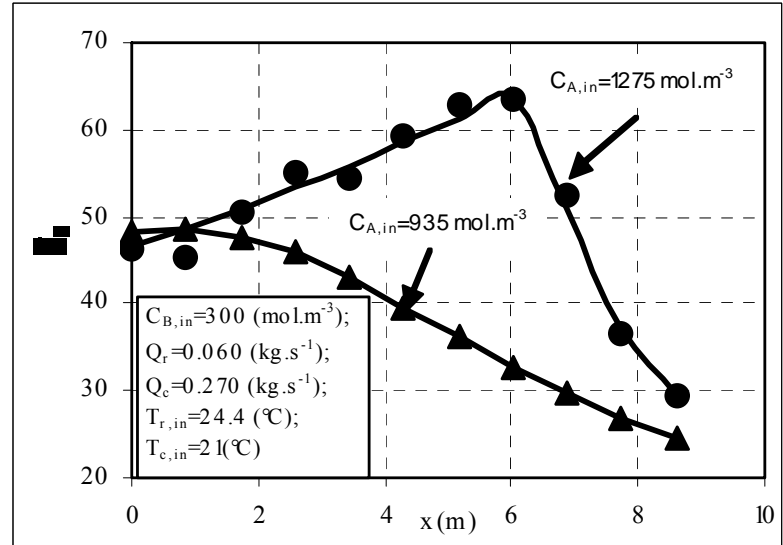

Fig. (11). Experimental and theoretical Temperature profile along the tubular reactor for two different concentration value of the hydrogen peroxide.

This figure shows the agreement between the theoretical and experimental results for both cases of hydrogen peroxide concentration. As discussed before, the increase of the concentration induces an increasing of the maximum temperature and shifts its localization toward the reactive fluid inlet.

\section{INFLUENCE OF THE SODIUM THIOSULFATE CONCENTRATION}

The influence of the concentration of sodium thiosulfate is reported in Fig. (12) for different values of the reactive fluid flow rate. The curves $(\mathrm{A})$ are relative to the maximum temperature value as function of $\mathrm{C}_{\mathrm{B}, \text { in }}$ and the curves (B) represent its localization versus $C_{B, i n}$. The maximum temperature is an increasing linear function according to the concentration of sodium thiosulfate.
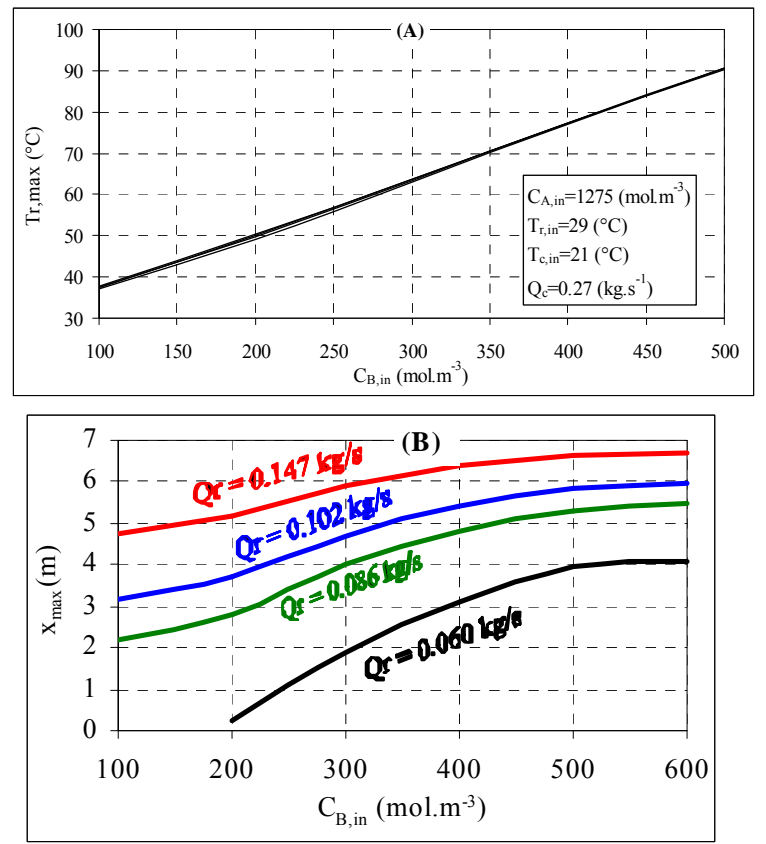

Fig. (12). Maximum temperature and its localization as function of the concentration of the sodium thiosulfate for different value of the reactive fluid flow rate.

$\mathrm{C}_{\mathrm{A}, \mathrm{in}}=1275\left(\mathrm{~mol} . \mathrm{m}^{-3}\right), \mathrm{T}_{\mathrm{r}, \text { in }}=29\left({ }^{\circ} \mathrm{C}\right), \mathrm{T}_{\mathrm{c}, \text { in }}=21\left({ }^{\circ} \mathrm{C}\right)$,

$\mathrm{Q}_{\mathrm{c}}=0.270\left(\mathrm{~kg} \cdot \mathrm{s}^{-1}\right)$ 
As indicated previously, the higher the concentration of sodium thiosulfate, the higher the importance of the energy released by the exothermic reaction. In this case, the maximum temperature is more important. The axial position increases with the concentration of sodium thiosulfate and seems to tend towards a limit value.

It is also interesting to visualize the evolution of the maximum temperature as function of its position as illustrated on Fig. (13).

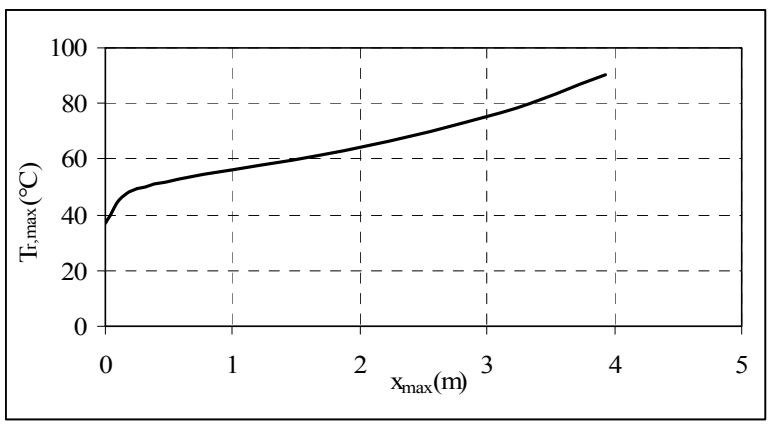

Fig. (13). Maximum temperature as function of its maximum temperature. tion.

The two parameters follow the same direction of varia-

In order to compare theoretical and experimental results, Fig. (14) shows the temperature profile along the tubular reactor for two values of the sodium thiosulfate concentration. The curve (A) and (B) are obtained respectively for a concentration of 545 and $300 \mathrm{~mol} . \mathrm{m}^{-3}$. The theoretical and experimental results are in good agreement.

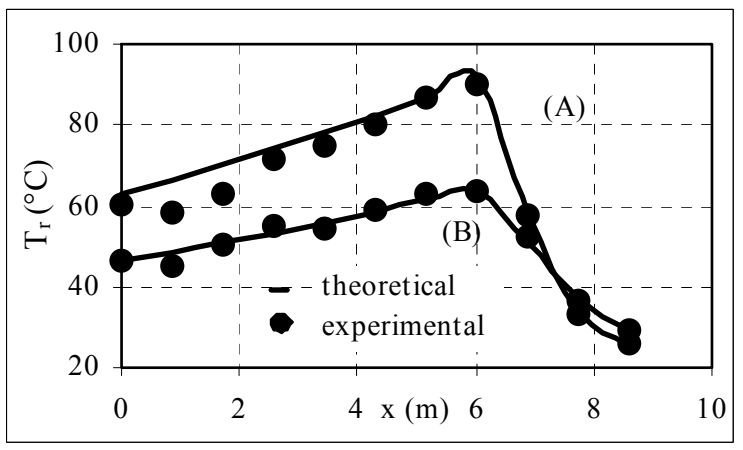

Fig. (14). Experimental and theoretical temperature of the reactive fluid along the tubular reactor for two different concentrations of the sodium thiosulfate.

The parameters used for the experiments of Fig. (14) are reported on Table 5 .

The maximum temperature increases with the concentration of sodium thiosulfate.

Table 5. Parameters Used for Fig. (7)

\begin{tabular}{|c|c|c|c|c|c|c|}
\hline & $\underset{\left(\mathbf{m o l} . \mathrm{m}^{-3}\right)}{\mathrm{C}_{\mathrm{A}, \mathrm{in}}}$ & $\underset{\left(\mathbf{m o l} . \mathrm{m}^{-3}\right)}{\mathbf{C}_{\mathbf{3}, \mathrm{in}}}$ & $\begin{array}{c}Q_{r} \\
(\mathrm{~kg} / \mathrm{s})\end{array}$ & $\begin{array}{c}\mathbf{Q}_{\mathrm{c}} \\
(\mathrm{kg} / \mathrm{s})\end{array}$ & $\begin{array}{l}\mathbf{T}_{\mathrm{r}, \mathrm{in}} \\
\left({ }^{\circ} \mathbf{C}\right)\end{array}$ & $\begin{array}{l}\mathbf{T}_{\mathbf{c}, \mathrm{in}} \\
\left({ }^{\circ} \mathbf{C}\right)\end{array}$ \\
\hline (A) & 1300 & 545 & \multirow{2}{*}{0.060} & \multirow{2}{*}{0.270} & 25.5 & \multirow{2}{*}{20.8} \\
\hline (B) & 1275 & 300 & & & 29.5 & \\
\hline
\end{tabular}

INFLUENCE OF THE INLET TEMPERATURE OF THE REACTIVE FLUID

As presented before, the inlet temperature of the reactive fluid influences significantly the chemical reaction kinetics. Consequently, the localization of the temperature is strongly related to the inlet temperature as illustrated on Fig. (15). The graph (A) of this figure shows the maximum temperature variation according to the reactive fluid inlet temperature for different values of flow rate Qr. The maximum temperature increases with the inlet temperature. With the same conditions, the graph (B) represents the maximum temperature localization for different values of the reactive fluid flow rate. The axial position of the maximum temperature is shifted toward the inlet of the reactive fluid when the inlet temperature increases.
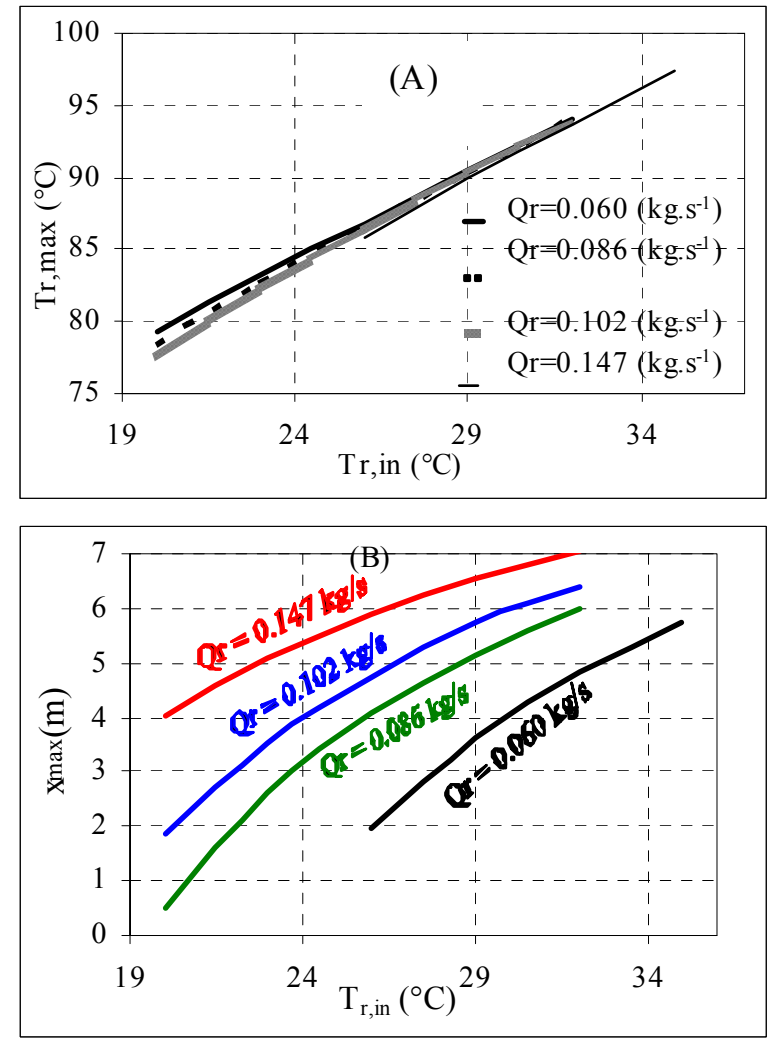

Fig. (15). Reactive fluid maximum temperature and its localization as function of its inlet temperature for different value of the reactive fluid flow rate.

$\mathrm{C}_{\mathrm{A}, \mathrm{in}}=1275\left(\mathrm{~mol} \cdot \mathrm{m}^{-3}\right) ; \mathrm{C}_{\mathrm{B}, \mathrm{in}}=500\left(\mathrm{~mol} \cdot \mathrm{m}^{-3}\right)$;

$\mathrm{T}_{\mathrm{c}, \mathrm{in}}=21\left({ }^{\circ} \mathrm{C}\right) ; \mathrm{Qc}=0.270\left(\mathrm{~kg} \cdot \mathrm{s}^{-1}\right)$

\section{CHARACTERISTIC TIME SENSITIVITY TO INLET PARAMETERS}

Characteristic time $\tau_{\max }$ was defined before as being the residence time of the reactive fluid to reach the position of its maximum temperature. The evolution of this characteristic time is studied according to the inlet concentrations of the two reagents and their inlet temperature. Fig (16) illustrates the variation of the characteristic time $\tau_{\max }$ according to the inlet concentration of hydrogen peroxide $\mathrm{C}_{\mathrm{A}, \mathrm{in}}$.

The characteristic time is a decreasing function versus $\mathrm{C}_{\mathrm{A}, \mathrm{in}}$. 
The sensitivity of this characteristic time to the inlet concentration of sodium thiosulfate is presented on Fig. (17).

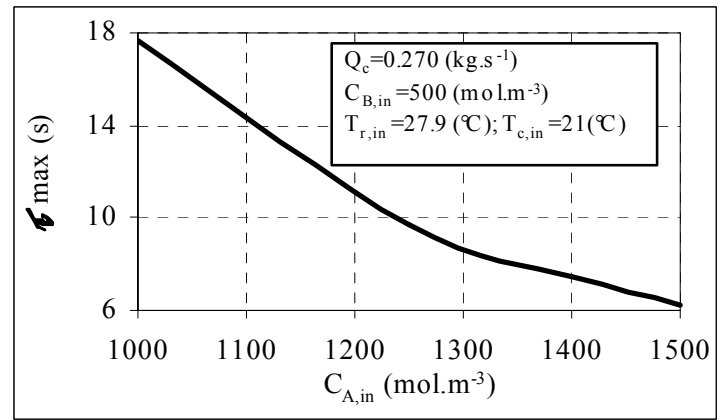

Fig. (16). Characteristic time as function of the inlet concentration of hydrogen peroxide.

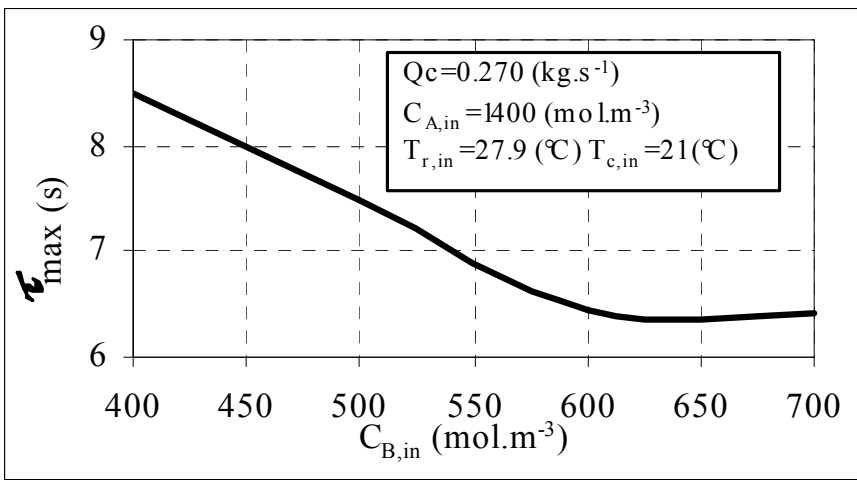

Fig. (17). Characteristic time as function of the inlet concentration of sodium thiosulfate.

In the same way, characteristic time decreases when the concentration $\mathrm{C}_{\mathrm{B} \text {,in }}$ increases. In both cases, when the concentration of one of the two reagents increases, the chemical reaction kinetics increase, and thus the maximum temperature is reached more quickly in the chemical reactor.

The variation of characteristic time according to the inlet temperature of this fluid is studied, since the advance of the reaction depends on it. Fig. (18) shows the evolution of $\tau_{\max }$ versus $T_{\mathrm{r}, \mathrm{in}}$.

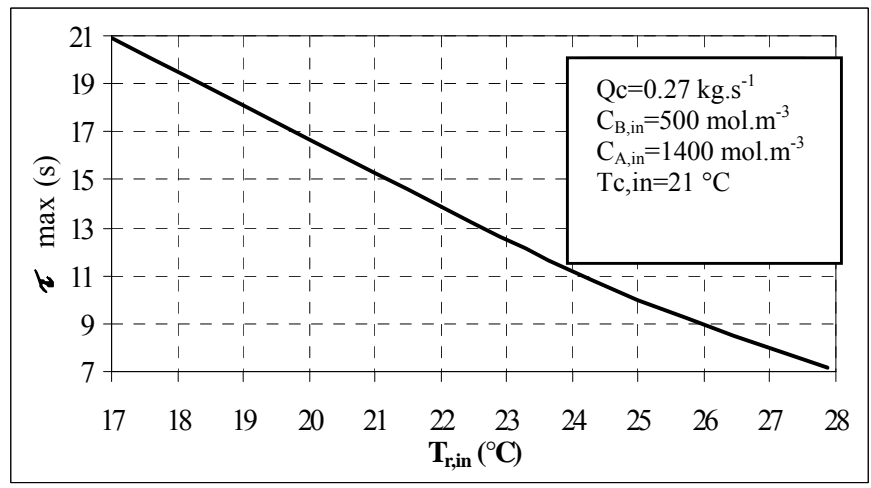

Fig. (18). Characteristic time as function of the inlet temperature of the reactive fluid.

The characteristic time decreases when the inlet temperature of the reactive fluid increases.

\section{CONCLUSIONS}

This work corresponds to a contribution to the safety of tubular reactors by investigating the experimental and theoretical localization of the axial position of the steady state maximum temperature according to various parameters along a tubular reactor in which an exothermic reaction between sodium thiosulfate and hydrogen peroxide is carried out. The localization of this maximum temperature represents a key parameter for safety in chemical engineering processes in order to anticipate the corrective actions. The steady state is obtained from the resolution of the model with the McCormack numerical method. The theoretical results are in good agreement with the experimental data obtained from the experimental set-up. The influence of the concentrations is investigated. The maximum value of the temperature increases and its position moves toward the inlet of the reactor when the concentration of hydrogen peroxide is more important. The maximum temperature is an increasing linear function according to the concentration of sodium thiosulfate. The axial position increases with the concentration of sodium thiosulfate and seems to tend towards a limit value. The influence of the inlet temperature is also a point discussed in this paper. The maximum temperature increases with this parameter and its axial position is shifted toward the inlet of the reactive fluid when the inlet temperature increases. The position of the maximum temperature is a linear function of the reactive fluid flow rate. A characteristic time corresponding to the residence time to reach the position of the maximum temperature is defined and investigated according to various parameters.

\section{NOMENCLATURE}

$\begin{array}{ll}\mathrm{A}_{0} & =\text { Frequency factor } \\ \mathrm{A} & =\text { Heat transfer area }\left(\mathrm{m}^{2}\right) \\ \mathrm{C} & =\text { Concentration }\left(\mathrm{mol} / \mathrm{m}^{3}\right) \\ \mathrm{C}^{*} & =\text { heat capacity }(\mathrm{J} / \mathrm{K}) \\ \mathrm{Cp} & =\text { Specific heat }(\mathrm{J} / \mathrm{kg} \cdot \mathrm{K}) \\ \mathrm{D} & =\text { Diameter }(\mathrm{m}) \\ \mathrm{e} & =\text { Thickness }(\mathrm{m}) \\ \mathrm{Ea} & =\text { activation Energy }(\mathrm{J} / \mathrm{mol}) \\ \mathrm{h} & =\text { Convective heat transfer coefficient }\left(\mathrm{W} / \mathrm{m}^{2} \mathrm{~K}\right) \\ \Delta \mathrm{H} & =\text { reaction enthalpy }(\mathrm{J} / \mathrm{mol}) \\ \mathrm{L} & =\text { Length }(\mathrm{m}) \\ \mathrm{Nu} & =\text { Nusselt number } \\ \mathrm{Pe} & =\text { Peclet number } \\ \mathrm{Pr} & =\text { Prandtl number } \\ \mathrm{Q} & =\text { Flow rate }(\mathrm{kg} / \mathrm{s}) \\ \mathrm{r} & =\text { Reaction rate } \\ \mathrm{R} & =\text { Constant } \\ \mathrm{Re} & =\text { Reynolds number } \\ \mathrm{S} & =\text { Heat transfer area }\left(\mathrm{m}^{2}\right) \\ \mathrm{T} & =\text { Temperature }\left({ }^{\circ} \mathrm{C}\right) \\ \mathrm{U} & =\text { Global heat transfer coefficient }\left(\mathrm{W} / \mathrm{m}^{2} \mathrm{~K}\right)\end{array}$ 


$$
\begin{array}{ll}
\mathrm{v} & =\text { Mean velocity }(\mathrm{m} / \mathrm{s}) \\
\mathrm{x} & =\text { Position }(\mathrm{m})
\end{array}
$$

\section{GREEK SYMBOL}

$\alpha \quad=$ Reaction parameter

$\beta=$ Reaction parameter

$\tau=$ Characteristic time

$\lambda=$ Thermal conductivity $(\mathrm{W} / \mathrm{m} . \mathrm{K})$

$\mu \quad=$ Dynamic viscosity $\left(\mathrm{kg} \cdot \mathrm{m}^{-1} \cdot \mathrm{s}^{-1}\right)$

$\mathrm{v} \quad=$ Stochiometric coefficient

$\rho=$ Fluid density $\left(\mathrm{kg} / \mathrm{m}^{3}\right)$

$\varphi_{\mathrm{i}} \quad=$ Accommodation factor

\section{INDEX}

$\begin{array}{ll}\mathrm{A} & =\text { Hydrogen peroxide } \\ \mathrm{B} & =\text { Sodium thiosulfate } \\ \mathrm{c} & =\text { Coolant fluid } \\ \mathrm{i} & =\text { Inner } \\ \text { in } & =\text { Input } \\ \max & =\text { Maximum } \\ \mathrm{r} & =\text { Reactant mixture } \\ \mathrm{w} & =\text { Wall }\end{array}$

\section{REFERENCES}

[1] E. Hamburger, G. Reggiani, J. Sambeth, and H. K. Wipf, "Seveso accident-its nature, extent and consequences", Ann. Occup. Hyg., vol. 22 (4), pp. 327-370, 1979.

[2] J. P. Gupta, "hit2The Bhopal gas tragedy: could it have happened in a developed country?", J. Loss Prev. Process. Ind., vol. 15 (1), pp. 1-4, 2002.
[3] R. Gygax, "Chemical reaction engineering for safety", Chem. Eng. Sci., Vol. 43 (8), pp. 1759-1771, 1988.

[4] A.-S. Vince, "Etat de l'Art des Méthodes Expérimentales d'Analyse de Risque de l'Emballement Thermique", final report, INERIS DRA 005, 2000.

[5] D.A. Crowl, J. F. Louvar, "Chemical process safety: Fundamentals with applications" (2nd ed.), New Jersey: Prentice Hall, 2002.

[6] F. Maestri and R. Rota, "Temperature diagrams for preventing decomposition or side reactions in liquid-liquid semibatch reactors", Chem. Eng. Sci., vol. (61) pp. 3068-3078, 2006.

[7] L. Vernières-Hassimi, "Estimation et localisation stationnaire et instationnaire de la temperature maximale pour la sécurité d'un réacteur chimique exothermique tubulaire, Doctorat, Université de Rouen, France, 2006.

[8] P. Medellin, and D. Luss, "Steady-state multiplicity and stability in a countercurrently-cooled tubular reactor", in fifth European and second International Symposium On Chemical Reaction Engineering, Amsterdam, 1972

[9] E.R. de Morais, E.C. Vasco de Toledo, and R. Maciel Filho, "Mixed coolant flow for optimal design of fixed bed catalytic reactors", Comput. Aided Chem. Eng., vol. 15 (2), pp. 978-983, 2003.

[10] E.R. de Morais, E.C. Vasco de Toledo, and R. Maciel Filho, "Alternative Designs for Fixed Bed Catalytic Reactors", Int. J. Chem. Reactor Eng., vol. 2, A28, 2004

[11] W.C. Cohen, J.L. Spencer, "Determination of chemical kinetics by calorimetry", Chem. Eng. Prog., vol. 58 (2), pp. 40-44, 1962.

[12] N. Aimé, "Aide à la conduite sûre des réacteurs chimiques discontinus en marche normale ou incidentelle vis-à-vis du danger d'emballement thermique", Doctorat, Université de Technologie de Compiègne, 1991.

[13] A.P. Colburn, "A method of correlating forced convection heat transfer data and comparison with fluid friction", Trans. Am. Inst. Chem. Eng., Vol. 29, pp. 174-210, 1933.

[14] H. Kawamura, "Analysis of transient turbulent heat transfer in an annulus: Part 1: Heating element with a finite (Nonzero) hart $\mathrm{Ca}-$ pacity and no thermal resistance", Trans J.S.M.E, vol. 39 (324), pp. 2498-2507, 1973.

[15] R.W. McCormack, "Numerical solution of the interaction of a shock wave with a laminar boundary layer", Lecture notes in phys$i c s$, vol. 8, Holt, M., Editor, Springer Verlag, New York, 1971. 